\title{
Multi-scale Microscopy of Microbially Induced Calcium Carbonate Precipitation
}

Neerja Zambare ${ }^{1,2}$, Ellen Lauchnor ${ }^{1,3}$, Robin Gerlach ${ }^{1,2}$, Betsey Pitts ${ }^{1}$

${ }^{1}$ Center for Biofilm Engineering, MSU, Bozeman, Montana

${ }^{2}$ Department of Chemical and Biological Engineering, MSU, Bozeman, Montana

${ }^{3}$ Department of Civil Engineering, MSU, Bozeman, Montana

Bacterially driven reactions such as ureolysis can induce calcium carbonate precipitation via generation of dissolved inorganic carbon and elevation of $\mathrm{pH}$, a well-studied process known as Microbially Induced Calcium Carbonate Precipitation (MICP). The series of reactions that take place during ureolysis driven MICP is shown by equations 1-3:

$$
\begin{aligned}
& \mathrm{CO}\left(\mathrm{NH}_{2}\right)_{2}+2 \mathrm{H}_{2} \mathrm{O} \stackrel{\text { urease }}{\longrightarrow} 2 \mathrm{NH}_{3}+\mathrm{HCO}_{3}^{-}+\mathrm{H}^{+} \\
& 2 \mathrm{NH}_{3}+\mathrm{H}^{+}+\mathrm{H}_{2} \mathrm{O} \leftrightarrow 2 \mathrm{NH}_{4}^{+}+\mathrm{OH}^{-} \\
& \mathrm{Ca}^{2+}+\mathrm{HCO}_{3}^{-} \rightarrow \mathrm{CaCO}_{3(\mathrm{~s})}+\mathrm{H}^{+}
\end{aligned}
$$

Bacteria containing the urease enzyme can induce urea hydrolysis, leading to the generation of ammonia, which equilibrates to ammonium raising the alkalinity of the fluid. As a result, the dissolved inorganic carbon concentration increases, and speciation shifts toward bicarbonate and carbonate. When calcium ions are present under these conditions, calcium carbonate can precipitate.

Ureolysis-driven MICP is being investigated for environmental applications such as sealing leakage pathways around wells or trapping groundwater contaminants such as heavy metals in precipitates. One of the most important aspects of MICP, for potential environmental applications, is the control of the spatial and temporal distribution of the calcium precipitates since it directly affects porous media properties such as porosity and permeability. Our studies in flow systems aim at characterizing and controlling $\mathrm{CaCO}_{3}$ distribution and $\mathrm{Sr}$ co-precipitation through MICP by manipulating fluid flow and calcium saturation conditions.

We employed a number of microscopy-based techniques to visualize the microbially induced calcium carbonate precipitates. Stereoscopy on glass beads used in a radial flow reactor revealed increasing amounts of precipitate with distance from the reactor inlet. Scanning Electron Microscopy (SEM) combined with Energy Dispersive Spectroscopy (EDS) allowed for the characterization of the precipitate morphology and elemental composition (Figure 1). SEM images (not shown here) also indicated an intimate association of bacterial cells with the produced precipitates. Calcium carbonate mineralogy was determined using X-Ray Diffraction (XRD). Stereoscopy analysis of entire rectangular flow cells (4 x 8 $\mathrm{cm}$ ) allowed to infer the formation of specific flow paths and estimates of the size of formed precipitates. Precipitates closer to the influent were considerably smaller than precipitates closer to the effluent (Figure 2). Laser Ablation coupled with Inductively Coupled Plasma Mass Spectrometry (LA-ICP-MS) was used to ablate precipitates. As the precipitates were volatilized by the laser, relative abundances of calcium and strontium were recorded throughout the flow cell. It was found that the ratio of strontium to calcium was higher closer to the inlet of the flow cells. Elemental analysis after spatially resolved acid digestion of the precipitates, corroborated the LA-ICP-MS observation that the smaller precipitates closer to the inlet exhibited higher strontium partitioning than the larger precipitates closer to the outlet (not shown here).

In our latest study, a microfluidic device was used to generate $50 \mu \mathrm{m}$ diameter micro-droplets containing single cells of ureolytic bacteria, and dissolved calcium to promote MICP. Over time, bacterial growth 
and MICP were observed in the droplets via Confocal Laser Scanning Microscopy (CLSM). Initial nucleation events and crystal growth over time were visualized. The inverted confocal microscope made it possible to distinguish bacterial cells (green) from the precipitate 'shells' growing around them (Figure 3.a). After 24 hours, precipitates from the droplets were collected and air-dried. SEM imaging revealed shell-like precipitate structures (Figure 3.b), aligning with the droplet diameters, indicating that under the conditions tested, droplet size was the limiting factor for precipitate diameter.

Preliminary microscopy results suggest that precipitate nucleation begins at the bacterial cell itself, with the crystal growing around the cell over time. The central 'origin' observed in the SEM images led to the hypothesis that as the crystal grows around the bacterial cell, the cell becomes encapsulated. Future microanalysis work will involve etching of a single crystal using Nano Auger Electron Microscopy to test for the presence of chemical signatures of life (nitrogen, phosphorus etc.) at the center of the precipitates.

(a)

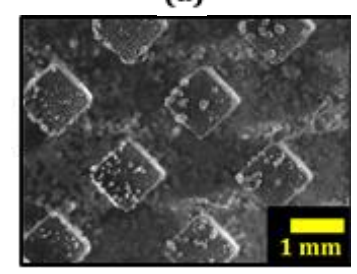

(b)

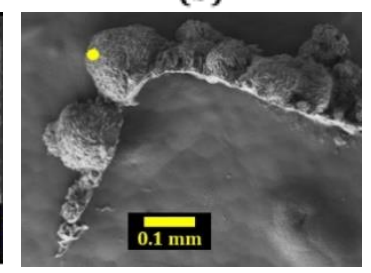

(c)

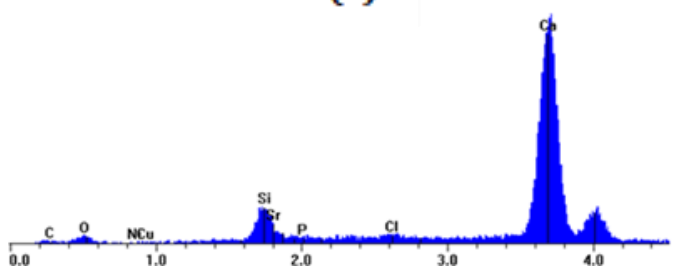

\begin{tabular}{|c|c|c|c|}
\hline Element & KRatio & Wt\% & At\% \\
\hline $\mathrm{C}$ & 0.0068 & 1.52 & 3.37 \\
$\mathrm{O}$ & 0.0607 & 30.93 & 51.34 \\
$\mathrm{Si}$ & 0.0671 & 5.73 & 5.42 \\
$\mathrm{P}$ & 0.0064 & 0.56 & 0.48 \\
$\mathrm{Cl}$ & 0.0116 & 0.87 & 0.65 \\
$\mathrm{Ca}$ & 0.8039 & 56.70 & 37.57 \\
$\mathrm{Ni}$ & 0.0009 & 0.07 & 0.03 \\
$\mathrm{Cu}$ & 0.0042 & 0.34 & 0.14 \\
$\mathrm{Sr}$ & 0.0385 & 3.27 & 0.99 \\
Total & 1.0000 & 100.00 & 100.00 \\
\hline
\end{tabular}

Figure 1: (a) Stereoscopy image showing calcium carbonate precipitates surrounding the polycarbonate pegs in the flow cell. (b) SEM image of precipitates from one of the pegs. The corner outline of the peg is clear in this image. (c) EDS spectra acquired at the location of the yellow dot in (b) indicate that strontium contained in the medium was co-precipitated with calcium carbonate.

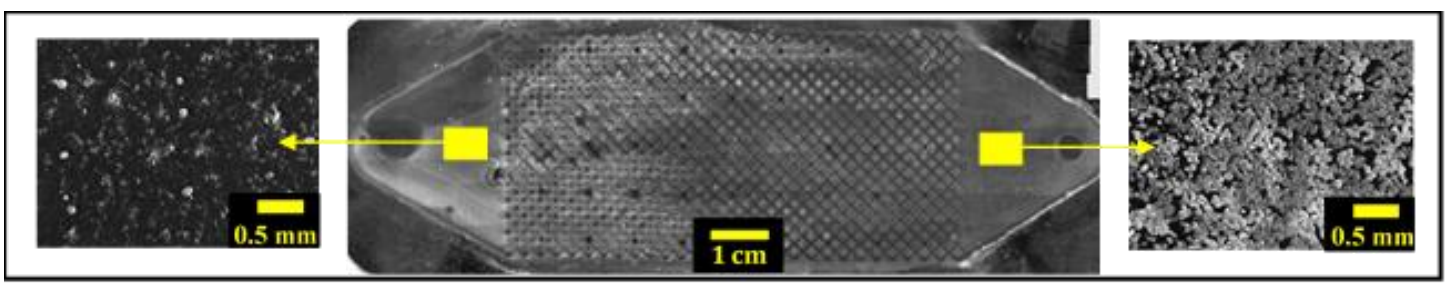

Figure 2: Entire flow cell imaged using stereoscopy. Smaller particulate precipitates formed closer to the influent while larger precipitates formed towards the effluent.
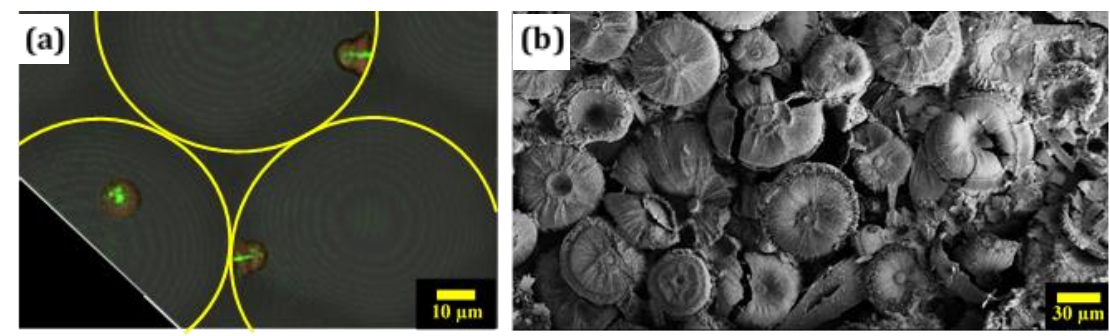

Figure 3: (a) $50 \mu \mathrm{m}$ diameter droplets containing E. coli MJK2 cells (green). (b) Dried precipitates imaged using an SEM showing shell-like precipitates approximately the diameter of the drops. 